\title{
A High Fidelity Model Based Approach to Identify Dynamic Friction in Electromechanical Actuator Ballscrews using Motor Current
}

\author{
Yameen M. Hussain ${ }^{1}$, Stephen Burrow ${ }^{2}$, Leigh Henson ${ }^{3}$, Patrick Keogh ${ }^{4}$ \\ ${ }^{1,2}$ University of Bristol, Bristol, BS8 1TR, United Kingdom \\ yameen.hussain@bristol.ac.uk \\ Stephen.Burrow@bristol.ac.uk \\ ${ }^{3}$ Stirling Dynamics Ltd, Bristol, BS8 4HG, United Kingdom \\ Leigh.Henson@stirling-dynamics.com \\ ${ }^{4}$ University of Bath, Bath, BA2 7AY, United Kingdom \\ p.s.keogh@bath.ac.uk
}

\begin{abstract}
An enhanced model based approach to monitor friction within Electromechanical Actuator (EMA) ballscrews using motor current is presented. The research was motivated by a drive in the aerospace sector to implement EMAs for safety critical applications to achieve a More Electric Aircraft (MEA). Concerns in reliability and mitigating the single of point of failure (ballscrew jamming) have resulted in consideration of Prognostics and Health Monitoring (PHM) techniques to identify the onset of jamming using motor current. A higher fidelity model based approach is generated for a true representation of ballscrew degradation, whereby the motor is modelled using ' $\mathrm{dq}$ axis' transformation theory to include a better representation of the motor dynamics. The ballscrew kinematics are to include the contact mechanics of the main sources of friction through the Stribeck model. The simulations demonstrated feature extraction of the dynamic behaviour in the system using $I_{q}$ current signals. These included peak starting current features during acceleration and transient friction variation. The simulated data were processed to analyse peak $I_{q}$ currents and classified to represent three health states (Healthy, Degrading and Faulty) using k-Nearest Neighbour (k-NN) algorithm. A classification accuracy of $\sim 74 \%$ was achieved.
\end{abstract}

Keywords- Prognostics; Health Monitoring; Aerospace; Electromechanical Actuators; Ballscrew; Fault Classification

\footnotetext{
Yameen M. Hussain et al. This is an open-access article distributed under the terms of the Creative Commons Attribution 3.0 United States License, which permits unrestricted use, distribution, and reproduction in any medium, provided the original author and source are credited.
}

\section{INTRODUCTION}

There is a move towards a MEA within the aerospace industry, which has prompted aircraft manufacturers to consider replacing traditional hydromechanical solutions for EMAs in actuation systems. This would fulfil the need for better maintainability, precision control and offer a weight saving advantage (Hoffman, Hansen, Beach, Plencner, Dengler, Jefferies \& Frye, 1985). EMAs are being considered in safety critical applications of next generation fly-by-wire aircraft (Balaban, Saxena, Narasimhan, Roychoudhury \& Goebel, 2011). This includes primary flight control systems and landing gear systems. The absence of reliable fail-safe mechanisms and adequate redundancy to mitigate the single point of failure (ballscrew jamming) has made it challenging to introduce EMAs in such safety critical systems (Balaban, Saxena, Bansal, Goebel, Curran \& Stoelting, 2009). PHM of such systems could mitigate ballscrew jamming, however, research in this area has revealed that the issue is complex for PHM designers due to the limitations in sensing. Aircraft manufacturers are reluctant to add more sensors due to added weight implications (Donald, Garg, Hunter, Guo \& Semega, 2004) and reduced reliability, hence PHM designers have to rely on motor current alone to detect the onset of ballscrew jamming. Therefore, the purpose of this paper is to demonstrate a means to monitor friction build up within the ballscrew using motor current for feature extraction and fault diagnostics.

\subsection{Background}

One of the major concerns has been EMA jamming which is a single point of failure. The mitigation of this failure mode could lead to a fully compliant and airworthy implementation 
for aircraft safety-critical systems. In view of this issue, significant research has been conducted by PHM designers in an attempt to detect and predict the onset of ballscrew jamming. EMAs consist of a motor, gearing and a ballscrew to provide incremental linear motion powered by the motor. Figure 1 shows a schematic of a typical EMA system.

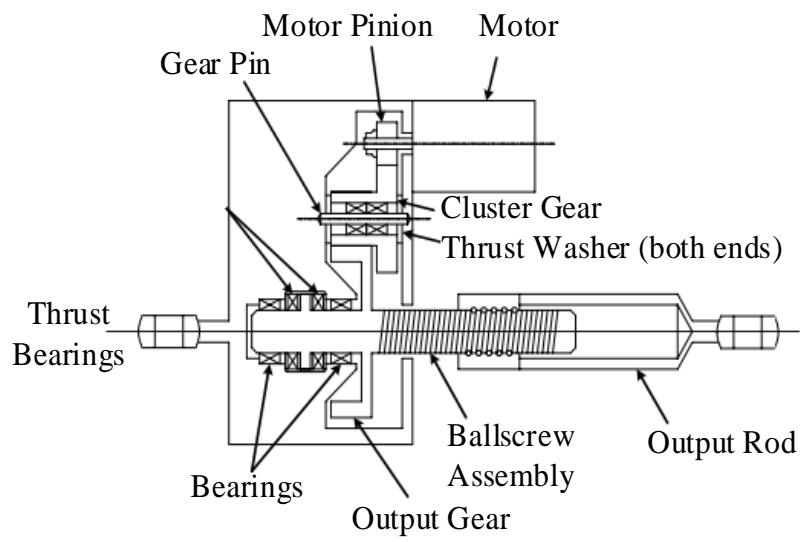

Figure 1. EMA System (Bodden, Clements, Schley \& Jenney, 2007).

It is known that EMAs can fail in many ways (Bennett, Mecrow, Atkinson \& Atkinson, 2010) with significant research conducted to achieve a fault tolerant EMA system to mitigate single points of failure. Much of this research has been centred around achieving fault tolerant designs for motor related failures for general applications. Motor rotor failures and short circuits are classed as one of the most severe types of failure as they can lead to a complete loss of operation at a system level. Within aerospace, however, there is adequate motor redundancy and therefore such failures would not inhibit operation of an EMA system (Bennett et al. 2010).

Mitigating ballscrew jamming in aerospace is of high importance as failure can lead to complete loss of operation of the landing gear extension/retraction or flight control system mechanism. The build up of friction and wear is identified as a precursor for ballscrew jamming (Lee, Lee, Hong, Nam, Jeon \& Lee, 2015). A reliable combination of sensing to monitor vibration, motor current, temperature and loads can be used to assess the condition of an EMA (Isturiz, Vinals, Manuel \& Aitzol, 2012). However, there is no guarantee that state-of-the-art sensing would be able to isolate the occurrence of a single point of failure such as ballscrew jamming. There are further limitations in which maintenance engineers have only motor current and speed/position data for fault detection in real applications. In addition, the presence of noise and external loads (due to gust and aeroloads) can make it challenging to identify degradation within the EMA mechanical sub-system using motor current alone. Therefore, diagnostics engineers must design a robust PHM algorithm to detect the onset of EMA jamming.

\subsection{Previously Published Work}

Research in this area has considered many strategies and technologies using PHM. Whilst research has been conducted in terms of applying PHM to EMAs, an optimum solution to mitigating jamming is still sought. This section reviews previously published work using a data-driven approach and a model based approach.

\subsubsection{Data-Driven Approach}

Research has been previously undertaken to isolate jamming failures by utilising test rig analysis for seeded failure tests and run-to-failure data. An example of this, is work undertaken by Balaban, Saxena, Goebel, Byington, Watson, Bharadwaj and Smith (2009) where jamming faults were injected into a custom made EMA test stand. The results showed good agreement with developed thermal and mechanical models. The issue, however, is the abrupt nature in which the failure occurs making it difficult to detect the onset of this failure. Bodden et al. (2007) also conducted seeded failure testing on an EMA test stand. The methodology evaluated actuator efficiency by monitoring overall power output against input. The analysis revealed that it was difficult to ascertain the origin of the fault at a local level.

Therefore, the main challenges in employing a data-driven analysis include the difficulty to simulate naturally occuring faults as well as isolating a particular fault within the drivetrain.

\subsubsection{Model Based Approach}

Modelling an EMA system in detail can enable the prognostics design engineer to trace back failure modes to relatable physical system parameters thus providing the engineer with informative diagnostic information. Maggiore, Vedova, Pace and Desando (2014) developed a Matlab/Simulink model of an EMA system for fault analysis associated with mechanical failures due to progressive wear. The modelled EMA system was typical of an arrangement for a primary flight control system comprising of control and power drive electronics, a Brushless Direct Current (BLDC) motor, gearing and a ball/rollerscrew. Importance was given to monitor to the build up of friction as a pre-cursor to the onset of jamming. The results showed that useful information could be obtained in terms of evaluating friction torque at a system level. However, it was not clear whether friction monitoring at a local level (for contentious regions within the ball/rollerscrew) could be characterisable, therefore making it challenging to diagnose for jamming faults.

Previous approaches have also generally used simple motor models. The investigation has therefore been limited to 
analysing electromagnetic torque and motor current without considering the dynamic effects of the motor. The research conducted by Maggiore et al. (2014) provided an advancement by modelling a BLDC system with power drive electronics that evaluated the torque generated by the motor as a function of the voltages generated by a 3-phase electrical power generator.

Therefore, identification ballscrew degradation within EMAs using motor current alone can be enhanced through modelling the magnetic behaviour of the motor to gain a more in-depth understanding of the motor dynamics. Detailed modelling of ballscrew kinematics should also be enhanced using a more accurate representation of the contact mechanics.

\subsection{Aims and Objectives}

This paper addresses the limitations of model based approaches that were described in Section 1.2.2 by providing an advancement to assessing ballscrew degradation through motor current signals. A high fidelity model of the EMA system is used to establish a link between motor current and ballscrew friction. It is proposed that such approach is used in conjunction with a data-driven approach, as part of a hybrid diagnostics approach. The primary objective of this paper is to determine the fidelity of friction monitoring within the ballscrew using motor current alone through feature extraction using a model based approach.

\section{Methodology}

The first part of the methodology consists of a series of procedures and equations for EMA modelling to develop an enhanced understanding of the baseline linear EMA system.

Secondly, the methodology describes how motor current can be used to aid fault detection and diagnostics of the ballscrew. This is followed by a description of the test cases and conditions to be simulated for healthy, degrading and failure states of the ballscrew.

Finally, the methodology describes the data analysis technique to be applied to the simulated data for each test case towards data training for classification.

\subsection{EMA Modelling}

The system being modelled is a baseline linear EMA system. The modelling was conducted using Matlab/Simulink where the key components consisted of the motor controller, the PMSM and the ballscrew. Figure 2 shows a high level view of the EMA system being modelled for speed and current control.

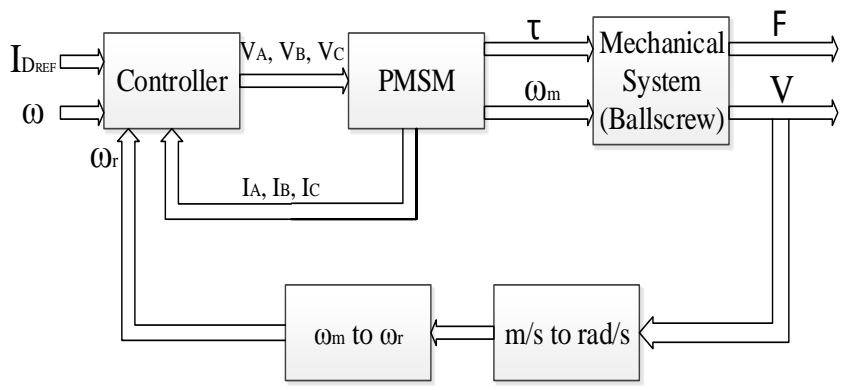

Figure 2. EMA Block Diagram.

PMSM's use permanent magnets rather than windings in the rotor. Electronic excitation control with integrated power inverter and rectifier, sensor, and inverter electronics are required for practical operation (Vas, 1996). The PMSM was modelled using 'dq-axis transformation' theory, which involves Park's transform. This reduces 3-phase AC quantities $\left(I_{a}, I_{b}, I_{c}\right)$ to DC quantities $\left(I_{d}, I_{q}\right)$ (Park, 1929). The transform to DC quantities reduces the complexity of the system and therefore more understanding of the drivetrain system can be achieved by modelling the PMSM in this way. Figure 3 shows the equivalent electrical circuit for the PMSM whereby, $R_{S}$ is the resistance, $L_{d}$ and $L_{q}$ are the inductances in the $\mathrm{d}$ and $\mathrm{q}$ axis respectively, $\omega_{r}$ is the angular velocity of the rotor, and $\lambda_{d}$ and $\lambda_{q}$ are the flux linkages in the $\mathrm{d}$ and $\mathrm{q}$ directions respectively.

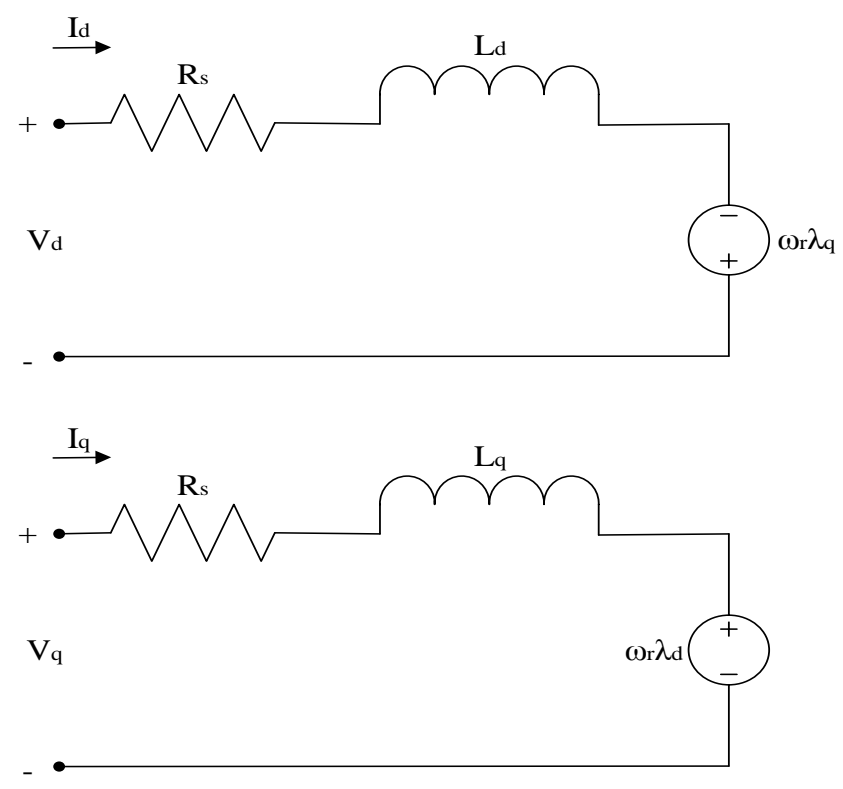

Figure 3. PMSM Equivalent Electric Circuit in Rotating Reference Frame (DQ).

The transformation converts vectors in the 3-phase reference frame to 2-phase and then a rotating 2-phase reference frame as shown in Figure 4. 


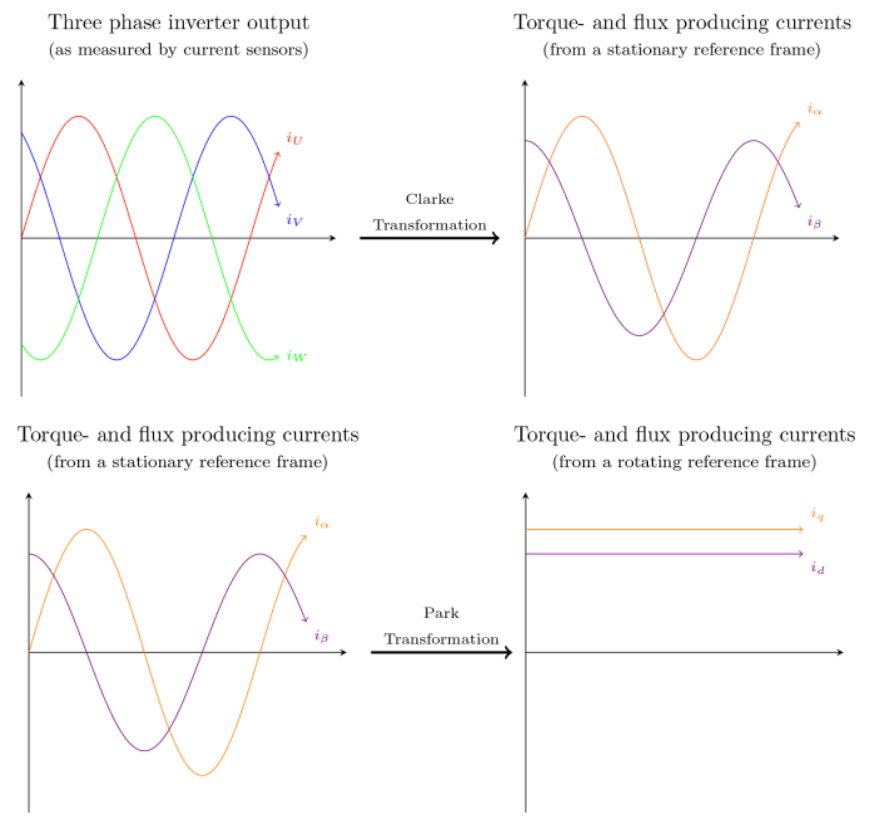

Figure 4. 3-phase to 2-phase Stationary (top) and 2-phase Stationary to 2-phase Rotating Reference Frame (bottom).

This enables simplified analysis of these DC quantities before performing the inverse transform to the 3 -phase results. This will provide in-depth motor understanding for condition monitoring and fault detection.

The PMSM was modelled in accordance to an industrial servomotor (Emerson) with parameters listed in Table 1.

Table 1. PMSM Parameters.

\begin{tabular}{ll}
\hline Parameter & Value \\
\hline Resistance, $R_{\mathrm{s}}$ & $1.1 \mathrm{ohm}$ \\
\hline Motor Voltage Constant, $K_{e}$ & $98 \mathrm{~V} / \mathrm{Krpm}$ \\
\hline Motor Torque Constant, $K_{t}$ & $1.6 \mathrm{Nm} / \mathrm{A}$ \\
\hline Peak Torque, $\tau$ & $45.9 \mathrm{Nm}$ \\
\hline Peak Current, $I$ & $28.7 \mathrm{~A}$ \\
\hline Poles, $p$ & 6 \\
\hline Inductance on q-axis, $L_{q}$ & $7.4 \mathrm{mH}$ \\
\hline Inductance on d-axis, $L_{d}$ & $7.4 \mathrm{mH}$ \\
\hline Motor Inertia, $J_{m}$ & $0.0138 \mathrm{~kg} \cdot \mathrm{m}^{2}$ \\
\hline
\end{tabular}

The electrical and mechanical elements of the PMSM were modelled within the PMSM block shown in Figure 2 using the equations listed in Section (i) of the Appendix.

The PMSM controller was modelled for speed and torque control. This enables real time control of torque variation demand, mechanical speed and regulation of the phase currents, which ultimately reduces the occurrence of current spikes during transient operation. Figure 5 shows a block diagram of the PMSM speed and current control system.

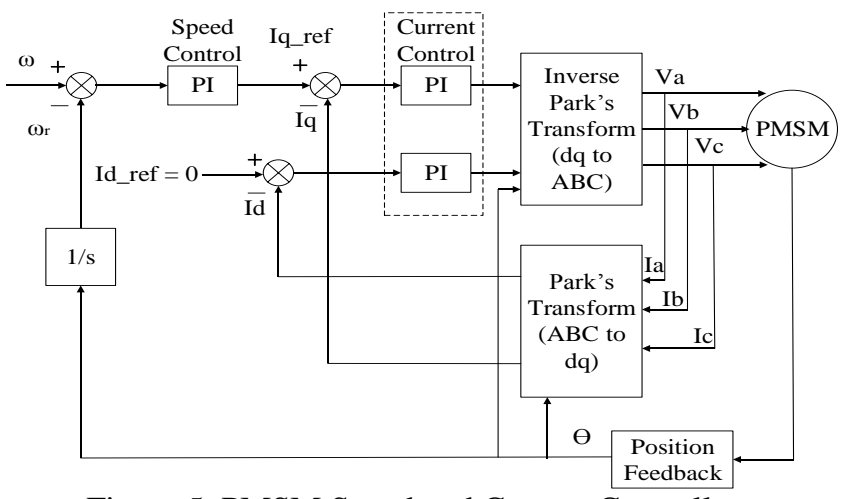

Figure 5. PMSM Speed and Current Controller.

The ballscrew was modelled by taking the generated mechanical torque and rotor speed values and converting them in to end loads and linear speeds. The ballscrew specification is presented in Table 2.

Table 2. Ballscrew Parameters.

\begin{tabular}{ll}
\hline Parameter & Value \\
\hline Lead, $L$ & 5 \\
\hline Length, $l$ & $300 \mathrm{~mm}$ \\
\hline Screw Diameter, $D_{s}$ & $16 \mathrm{~mm}$ \\
\hline Ball Diameter, $D$ & $3.15 \mathrm{~mm}$ \\
\hline Ballscrew Lead Angle, $\alpha$ & $7^{0}$ \\
\hline Density, $\rho$ & $7750 \mathrm{~kg} / \mathrm{m}^{3}$ \\
\hline $\begin{array}{l}\text { Ballscrew coefficient of } \\
\text { friction, } \mu\end{array}$ & 0.01 \\
\hline
\end{tabular}

The equations used for ballscrew modelling are listed in Section (ii) of the Appendix.

Friction is mostly prevalent between the ball and screw thread (Vahid-Araghi \& Golnaraghi, 2011). Friction also occurs between the ball and nut and therefore the analysis focuses on these areas of interaction within the ballscrew. A kinematic analysis of this region was required in order to understand these contact areas in more detail and to evaluate friction as a function of sliding velocity. A schematic depicting the ballscrew kinematics is shown in Figure 6.

A thorough mathematical model of ballscrew kinematics has been developed by Wei and Lin (2004), therefore this was utilised partially for this segment of the research. 


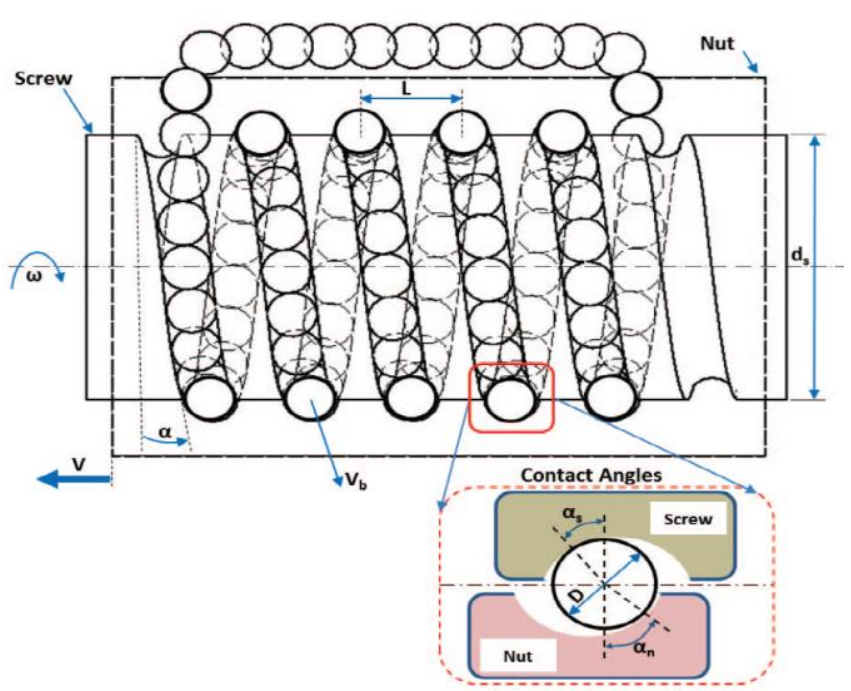

Figure 6. Ballscrew Kinematics (Ismail, Balaban \& Spangenberg, 2016).

In order to calculate the relative angular velocities $\left(\omega_{B S}\right.$ and $\omega_{B N}$ ), ball linear velocity, $V_{b}$ needs to be ascertained. Derivation of ballsrew relative angular velocities are shown in Section (ii) of the Appendix.

The next step is to formulate a velocity dependent coefficient of friction model given the relative velocities between the ball and nut, and ball and screw. The Stribeck friction model (Bowden \& Tabor, 1950) was used to evaluate friction between the interacting surfaces in the ballscrew. This was used previously by Vahid-Araghi and Golnaraghi (2011) for a lead screw drive system. The velocity depdendent coefficient of friction is generally composed of:

(a) Coulomb friction, $F_{c}$ - Constant friction force opposing motion.

(b) Viscous friction, $F_{v}$ - Friction force proportional to the sliding velocity.

(c) Stribeck friction, $F_{s}$ - Occurs at low sliding velocities and contains Coulomb and Viscous friction components as shown in Figure 7.

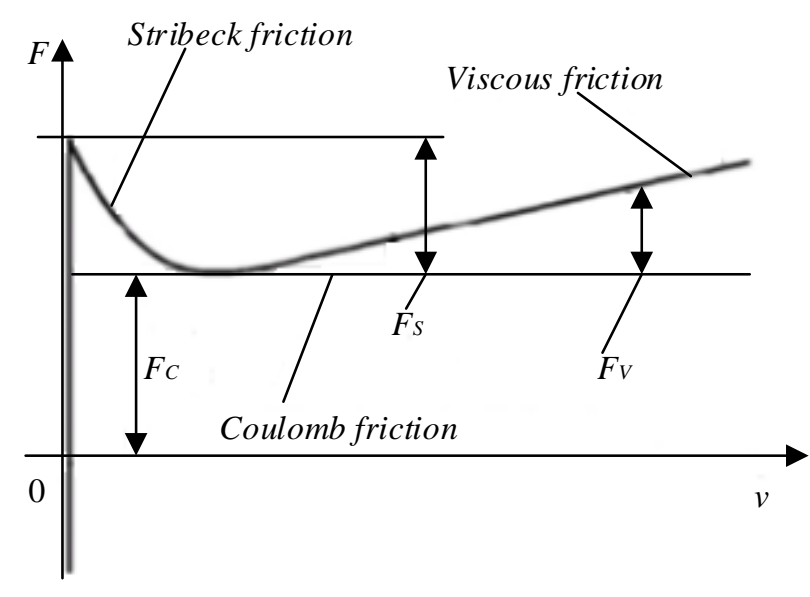

Figure 7. Velocity Dependent Coefficient of Friction.

$F=F_{c}+F_{s}\left(e^{-\left(\frac{\left|v_{s}\right|}{v_{0}}\right)}-1\right)+F_{v}\left|v_{s}\right|$

where $v_{s}$ is the sliding velocity between interacting surfaces. This was treated as the relative speed between ball and nut, and ball and screw as described earlier in this section. $v_{0}$ controls the velocity range of the Stribeck effect.

The overall friction is then added into the end load model, which is then converted back into the reflected torque to the motor.

\subsection{Test Cases and Conditions}

Using the model described in Section 2.1, a series of simulations were evaluated using different variables that include contact angles between ball and nut, and ball and screw, mechanical efficiencies and demand speeds. A typical landing gear extension/retraction cycle for a Boeing 757 is required to complete in $\sim 20$ seconds (Boeing, 1994) therefore a cycle time of 20 seconds was used for this analysis.

One of the primary objectives of this paper is to identify the onset of ballscrew jamming using a model based approach therefore test cases for simulation were created with respect to 3 states of health: Healthy, Degrading and Faulty.

\section{Healthy State}

Contact angles between ball and nut, and ball and screw typically range between $38-40^{\circ}$ (Ninomiya \& Miyaguchi, 1998). Therefore, these values were used to represent a healthy condition for the ballscrew and nut.

Mechanical efficiency is the measure of effectiveness of the EMA's input power over the output, which produces the end force and motion. Industry standard values were used for 
ballscrew mechanical efficiency which is generally in the region of $\sim 80-90 \%$ for healthy states (McNier, 2016).

\section{$\underline{\text { Degrading State }}$}

Degrading states are conditions where the EMA is operable, but exhibits deteriorations in performance due to wear and build up of friction. Ballscrew and nut contact angles can vary upto $8 \%$ through deterioration, misalignment cases or incorrect selection (Xu, Yao, Sun \& Shen, 2014). Therefore such instances were simulated by inducing variation in the contact angles of up to $8 \%$.

Ballscrew mechanical efficiencies are also significantly lower therefore values between $35-65 \%$ were used in this state. Mechanical efficiencies of $70-80 \%$ were also tested for such cases of variation in contact angles.

\section{Faulty State}

The analysis is focused on one type of EMA failure mode, ballscrew jamming. The onset of jamming is of interest and so lower mechanical efficiency values (15-35\%) were modelled to evaluate the effect on motor current.

The relative velocities (between ball and nut, and ball and screw) were set to zero to represent the jamming condition.

Table 3 summarises the test cases and conditions that were simulated.

Table 3. Test Cases and Conditions Summary.

\begin{tabular}{lll}
\hline State & $\begin{array}{l}\text { Ball - Nut and Ball } \\
\text { - Screw Angle of } \\
\text { Contact (degrees) }\end{array}$ & $\begin{array}{l}\text { Mechanical } \\
\text { Efficiency } \\
(\mathbf{\%})\end{array}$ \\
\hline Healthy & $38-40$ & $70-80$ \\
\hline Degrading & $35-43$ & $70-80$ \\
\hline Faulted & $\begin{array}{l}\text { Relative velocity set } \\
\text { close to 0 (onset of } \\
\text { jamming) }\end{array}$ & \begin{tabular}{l}
$35-65$ \\
\hline
\end{tabular} \\
\hline
\end{tabular}

The contact angles were modelled (see Appendix) using Equations (26) and (27) and were varied according to the values listed in Table 3 (in radians). The mechanical efficiencies were modelled using industry standard viscous friction coefficients. Figure 8 shows a graph by THK (2017) indicating typical ballscrew viscous coefficients corresponding to overall efficiency.

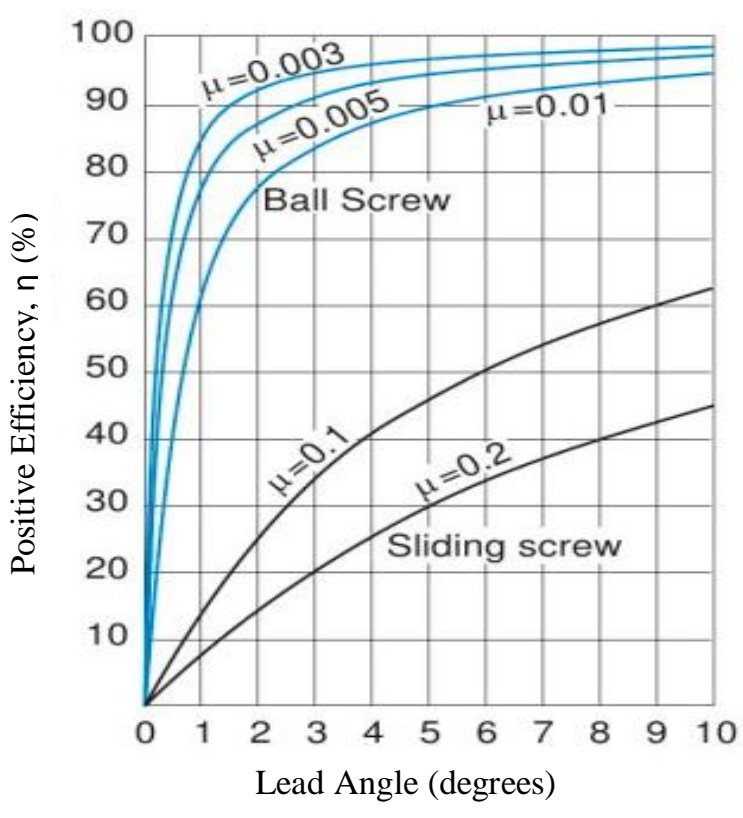

Figure 8. Ballscrew Efficiency (THK, 2017).

The ballscrew lead angle was calculated using Equation (22), from which subsequent values of viscous friction coefficients were deduced accordingly to represent each health state. The values of viscous friction coefficient were modelled in Equation (1).

Simulations for each of the test cases for the different states were run for different motor command speeds: 500, 1500 and 3000 RPM.

In addition, external disturbances can occur in an EMA application, e.g. gust and aeroloads for a landing gear actuation system, which can induce uncertainty in ascertaining the true state of health. Therefore, instantaneous loads through a single cycle were modelled to replicate these disturbances. These loads were simulated by applying a load factor $(\times 1.2)$ at a constant level throughout cycle.

Following the simulations, peak $I_{q}$ motor currents were generated for post analysis and training for classification. A total of $667 I_{q}$ current datasets were generated which included different contact angle combinations and mechanical efficiencies (as shown in Table 3) as well as variations due to external disturbances for each of the test cases.

\subsection{Data Classification}

Classification of all the data was necessary in order to train and learn from the parameter readings for new data.

The classification of the simulated data was viewed as a process of 'supervised learning' from which the objective 
was to take the known set of input data and known responses to the data, and build a prediction model for responses to new data.

Various algorithms were considered for applying data classification techniques. These classification algorithms (for supervised learning) included decision trees, Support Vector Machine (SVM), Discriminant analysis, k-NN and Naïve Bayes. The selection of the classification algorithm was based on prediction accuracy, fitting and prediction speed and ease of interpretation.

Karter (2016) reviewed the use of these algorithms. Decision trees for classification was considered binary and therefore have low predictive accuracy. SVMs have high predictive accuracy and the data would need to have exactly two classes. If many support vectors are used, prediction speed and memory become compromised. k-NNs have good predictive accuracy in low dimensions even with large datasets. Discriminant analysis can have varying predictive accuracies depending on the modeling assumptions.

Therefore, given high predictive accuracy for large datasets with low dimensions, the datasets were trained and classified using the k-NN algorithm. This stores all trained cases and classifies new cases based on a measure of similarity (Murphy, 2012). By this, the k-NN algorithm measures the distance between a new scenario against the already set scenarios from the generated data sets which would enable an approximation for classification for a new query. Distance was evaluated using the Euclidean norm (Murphy, 2012):

$d_{s t}^{2}=\left(x_{s}-y_{t}\right)\left(x_{s}-y_{t}\right)^{\prime}$

The datasets generated from Section 2.2 were organised and trained for all the different tests conditions and cases for classification using peak motor current values only. This was tested to evaluate the robustness and accuracy for new queries. New queries were selected for classification prediction using k-NN classifier. This was achieved using the built-in k-NN function in Matlab, the code for which can be found in the Appendix.

\section{Simulations}

This section is divided into two parts. The first shows the simulation results of the test cases described in Section 2.2. The second contains the analysis and classification of the trained data with new queries tested using k-NN classification algorithm.

\subsection{Simulation Results}

Simulations were run for three trapezoidal speed profiles 500, 1500 and 3000 RPM as shown in Figure 8.

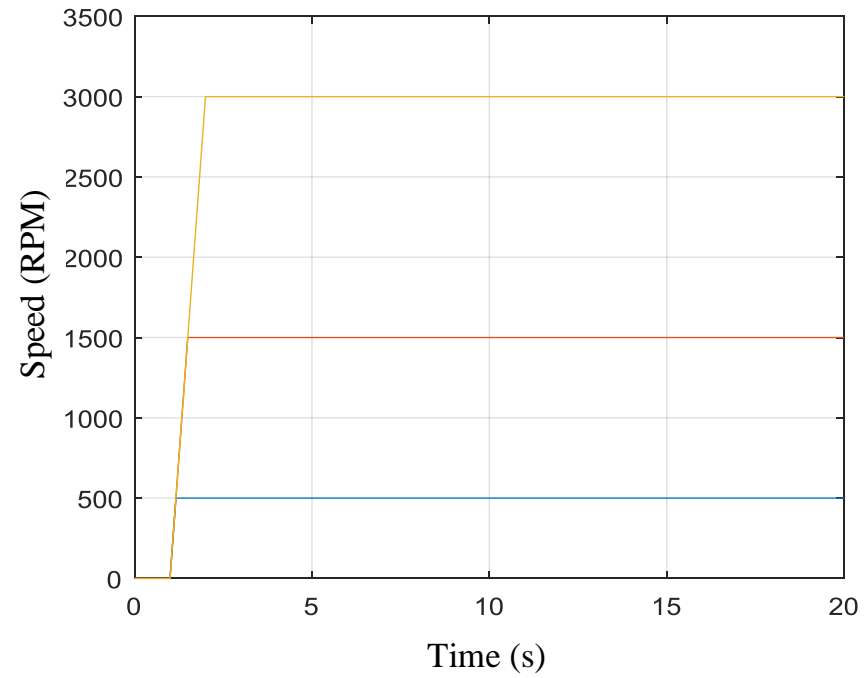

Figure 9. EMA Test Speed Profiles.

The corresponding 3-phase currents for 500 RPM is shown in Figure 9.
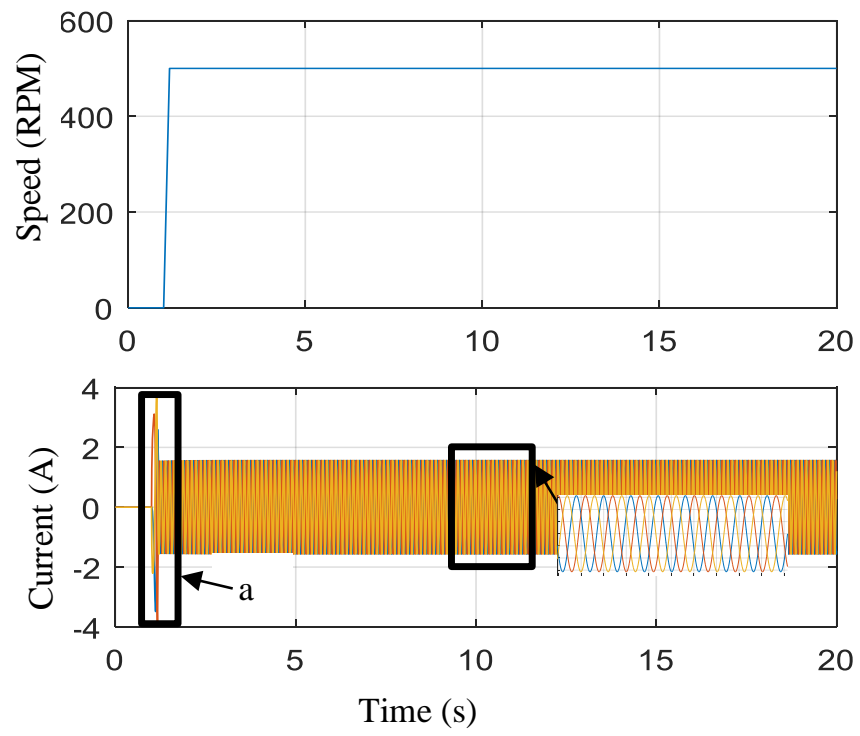

Figure 10. 3-Phase Currents at 500 RPM.

As can be seen from the region labelled 'a' in Figure 9, the motor starts to turn after 1 second, which corresponds to the initial ramp up as indicated in the speed profiles and is followed by a peak starting current. After reaching steady state, the sinusoidal 3-phase alternating currents exhibit constant amplitudes as well as fixed width waveforms.

The peak starting current occurs when an electrical motor is switched on in which the magnitude of the current drawn is dependent on the initial load on the motor (Park, 1929). Gao and Kang (2014) demonstrated this effect through the 
modeling of a PMSM using vector control, with results shown in Figure 11.

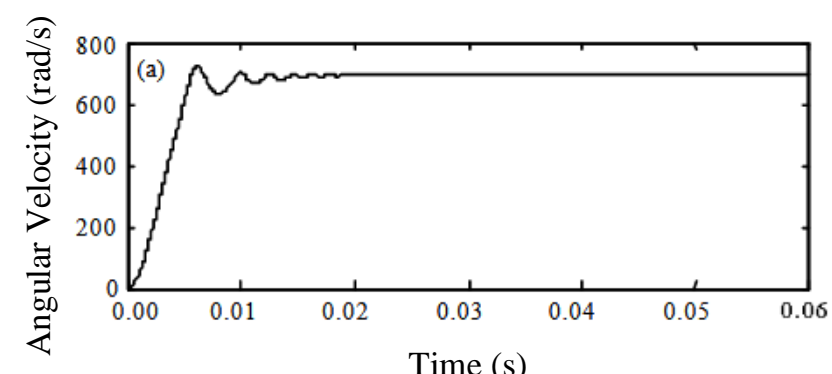

Time (s)

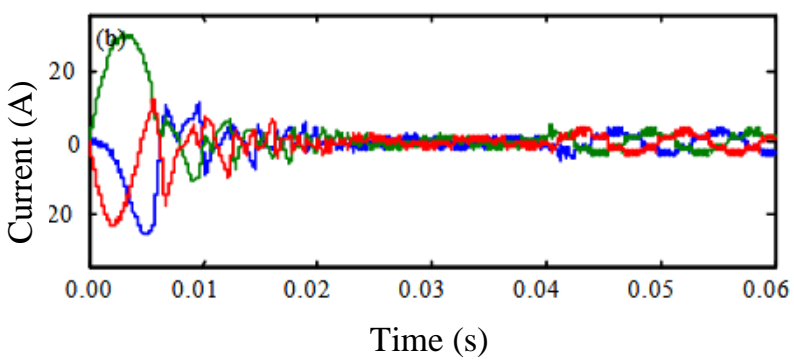

Figure 11. Modelled Speed and Current Response of a PMSM during Start-up (Gao \& Kang, 2014).

Park's transform was performed to generate the equivalent $I_{q}$ currents. These are shown for all speeds in Figure 12.

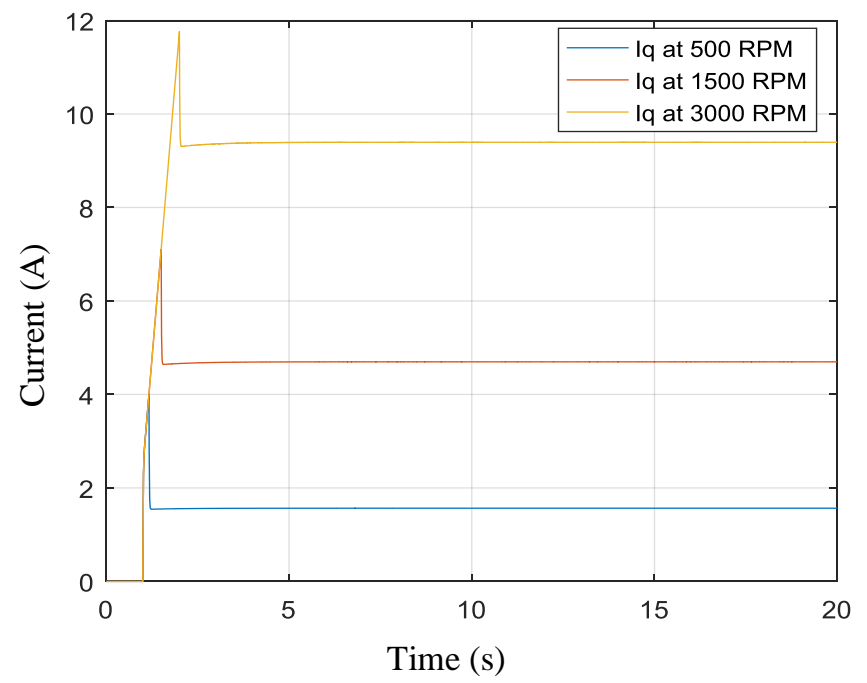

Figure 12. $I_{q}$ Currents for All Speeds.

The transient period (at the first peak of the starting current) increases with command speed due to acceleration before settling to steady state currents. The next set of simulations were conducted to evaluate the effects of the ballscrew kinematics. Figure 13 shows the time domain 3-phase and $I_{q}$ current signals without any load torque at 500 RPM.
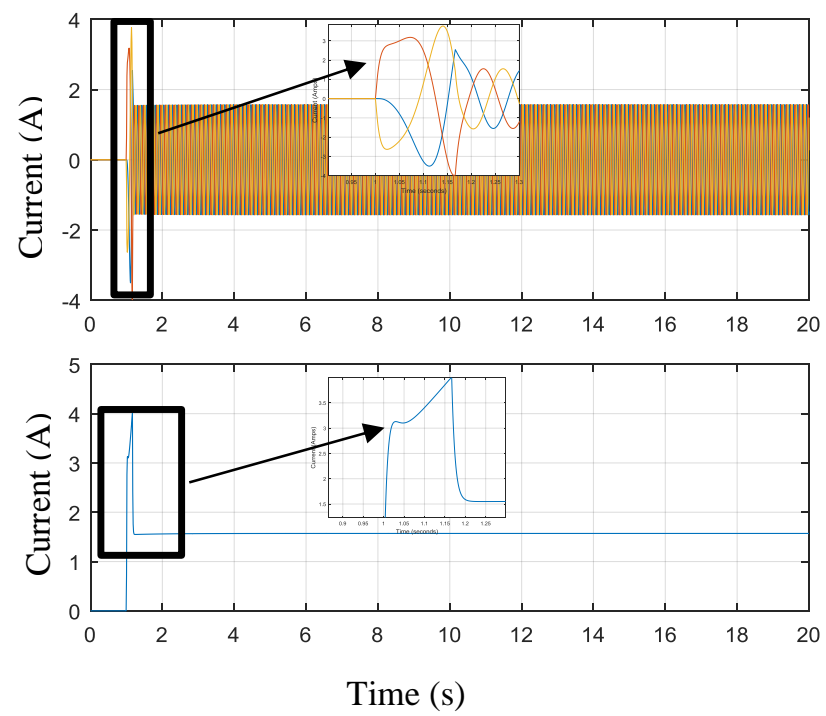

Figure 13. 3-phase and $I_{q}$ Currents at 500 RPM with Ballscrew.

The zoomed views in Figure 13, in addition to the peak starting current show an additional current spike at the beginning of the starting current region. This is attributable to the Stribeck friction component of the ballscrew friction model. This occurs at low velocities at a transition between static and kinetic friction. This is further exemplified in Figure 14 when the Stribeck friction coefficient is increased.

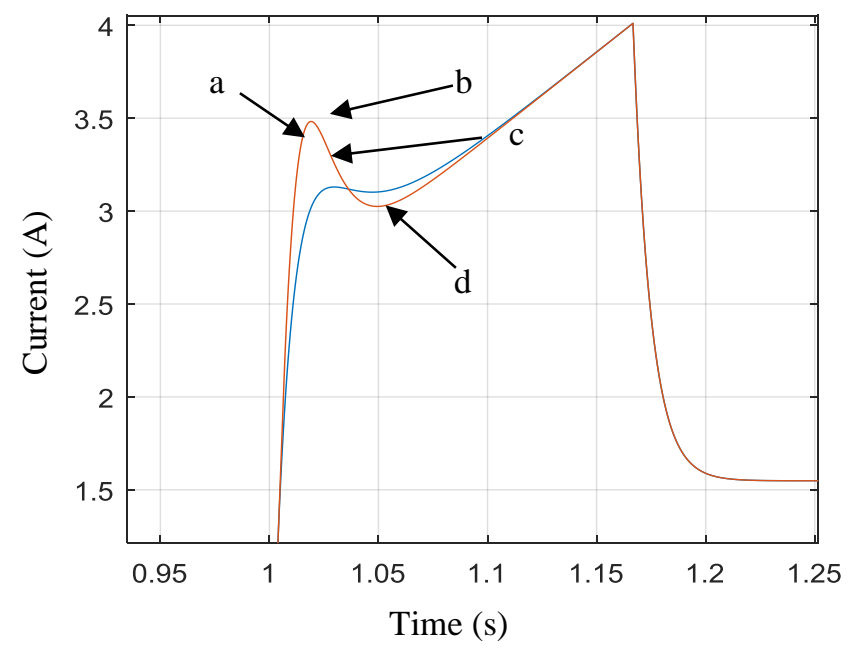

Figure 14. $I_{q}$ Current with Increased Stribeck Effect in Ballscrew.

This effect can be described further as stick and slip between two contact areas. With regards to Figure 14, region ' $a$ ' is the static region from which the interaction behaves like a spring with micro-displacement proportional to the force (Armstrong-Helouvry, Dupont, \& De Wit, 1994). Region 'b' exhibits boundary lubrication whereby the velocity increases, however, it not enough to build a fluid film between the 
surfaces. Region 'c' involves partial fluid lubrication and region ' $d$ ' includes full fluid lubrication whereby the relatively velocity is high enough for separation of the surfaces (Armstrong-Helouvry et al, 1994).

Figure 15 shows a range of peak current values (from steady state behavior) against speed for the motor only as well as for the motor + ballscrew configurations (with Stribeck friction conditions as described above).

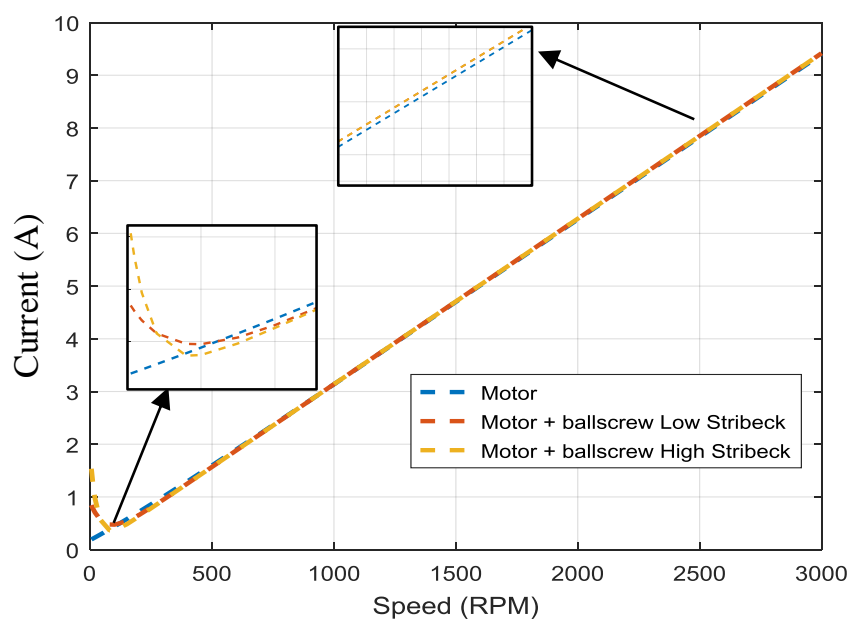

Figure 15. $I_{q}$ Current Speed Range with Stribeck Effect.

For the 'motor only' configuration, the currents increase linearly due to the velocity dependent internal friction of the motor. This is also true for configurations with ballscrew included, however, there is a gradually increasing disparity in current with speed due to the presence of ballscrew viscous friction component. Furthermore, higher current is noticeable at lower speeds due to the Stribeck effect for the motor + ballscrew configurations.

Jeong and Cho (2002) analysed these effects through an experimental study evaluating the cutting force of a ballscrew driven milling machine using motor current. Figure 16 shows the behaviour of the motor current due to the Stribeck effect at lower velocities.

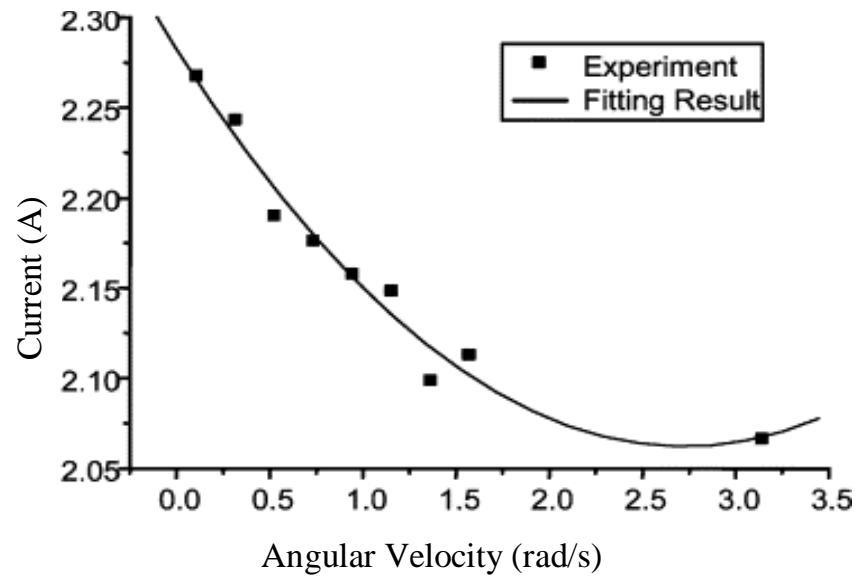

Figure 16. Relationship Between Angular Velocity and Motor Current - Stribeck Effect (Jeong \& Cho, 2002).

As inferred through the motor current, the transition to Coulomb friction occurred before transitioning to Viscous friction, whereby the friction force is proportional to velocity, as Jeong and Cho (2002) demonstrated in Figure 17.

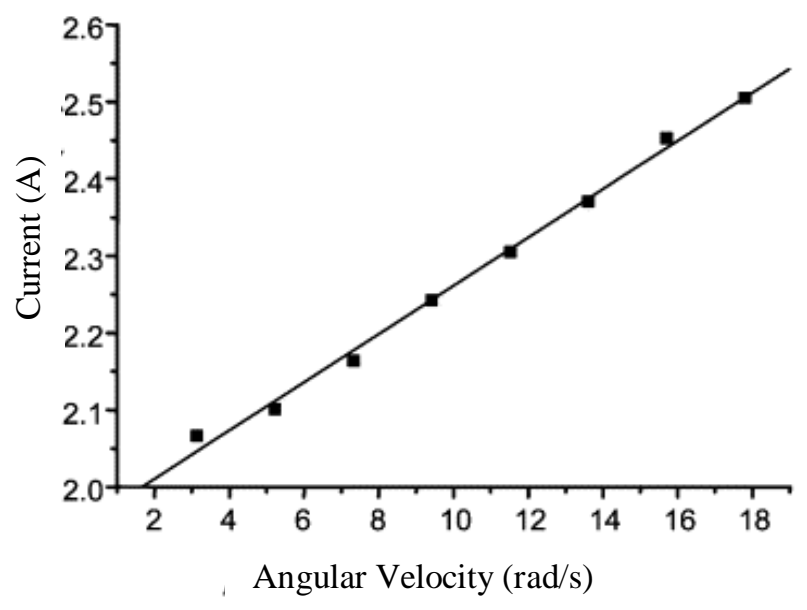

Figure 17. Relationship Between Angular Velocity and Motor Current - Linear Region (Jeong \& Cho, 2002).

Jeong and Cho (2002) also showed experimentally different cutting forces to evaluate the effects of load torque generation through motor current (Figure 18). 


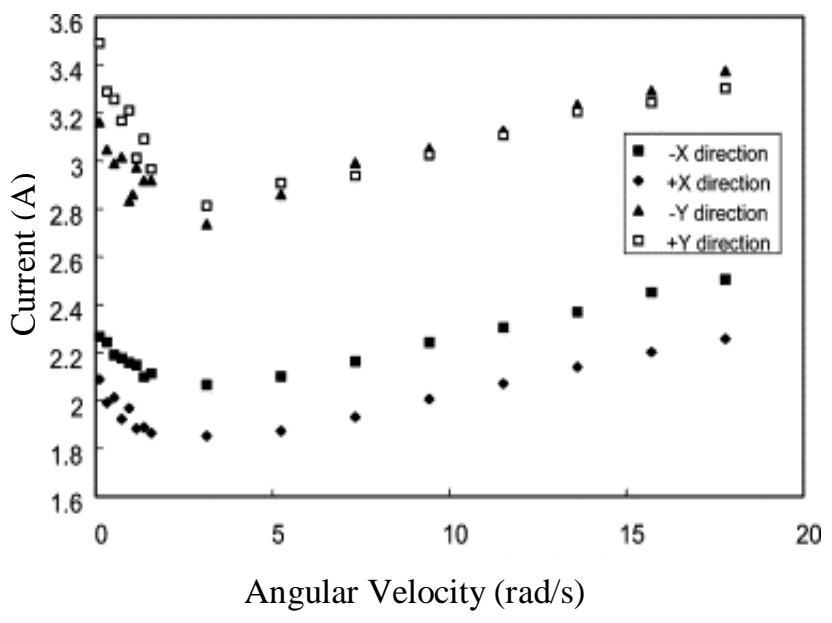

Figure 18. Relationship Between Angular Velocity and Motor Current for Different Cutting Forces (Jeong \& Cho, 2002).

The effects of viscous friction through motor current signals were simulated. Figure 8 in Section 2.2 provided a guideline to use for representative viscous friction values as an indicative figure of ballscrew efficiency from industry standards. Progressively higher values of viscous friction were used to represent a degrading and faulty ballscrew system. Resulting peak $I_{q}$ currents across a speed range are shown in Figure 19.

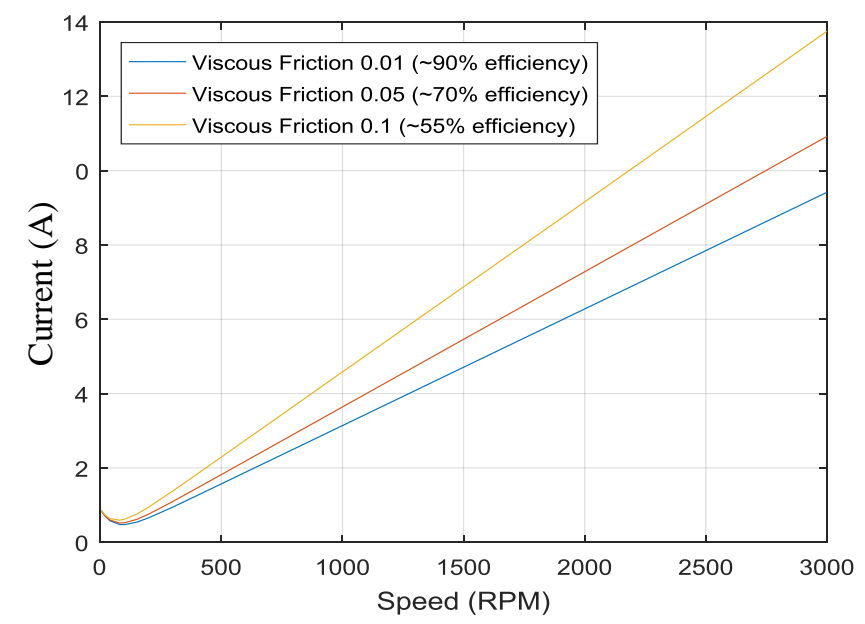

Figure 19. $I_{q}$ Current Variation with Viscous Friction.

As can be observed, the $I_{q}$ currents increase with viscous friction, which is speed dependent. Hence, disparities between each condition become larger with speed.

The next step evaluated the effect of seeding a fault (change in ball and nut, and, ball and screw contact angle) on 3-phase and $I_{q}$ current signals. A simulation was run at 500 RPM with a seeded fault in the form of a contact angle variation was modelled at 10 seconds.
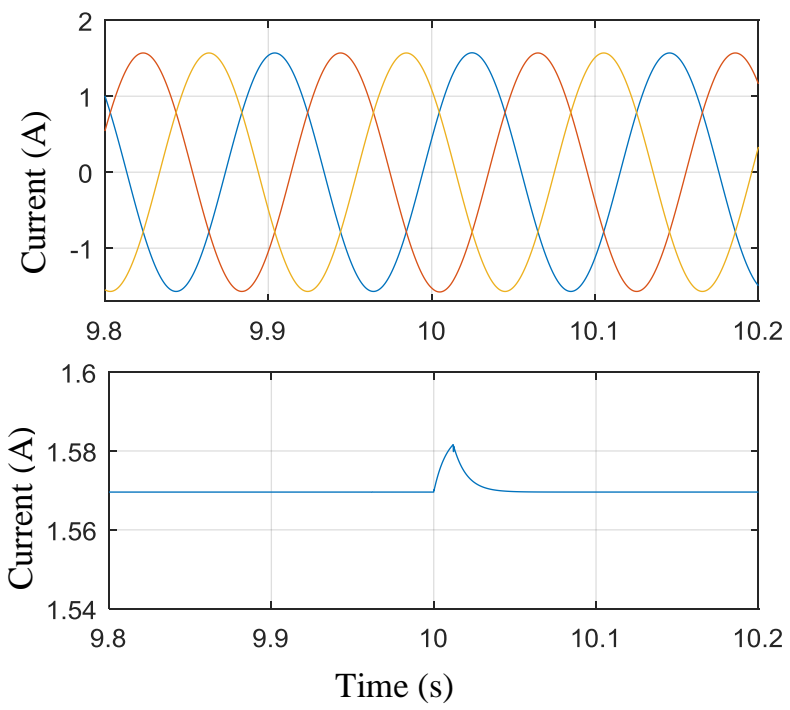

Figure 20. 3-phase Current (top) and $I_{q}$ Current (bottom) Signals Following Seeded Fault.

From Figure 20, a resulting spike is noticeable through evaluation of the $I_{q}$ current. Such method can be used to determine variation in ballscrew geometry for fault detection.

Simulations were then run for different contact angles and mechanical efficiencies added to evaluate the effect of $I_{q}$ currents. The analysis considers the maximum $I_{q}$ current from steady state period for each test case. Results are shown for Healthy, Degrading and Faulty conditions.

\section{$\underline{\text { Healthy State }}$}

Firstly, the contact angles (between ball and nut, and ball and screw) were varied (as specified in Table 3). The resulting maximum $I_{q}$ currents are shown in Table 4 for all speed demands with $80 \%$ mechanical system efficiency.

Table 4. Maximum $I_{q}$ Currents Under Varying Contact Angles for All Speeds (Healthy States).

\begin{tabular}{lllll}
\hline $\begin{array}{l}\text { Test } \\
\text { Case }\end{array}$ & $\begin{array}{l}\text { Demand } \\
\text { Speed (RPM) }\end{array}$ & $\begin{array}{l}\text { Contact } \\
\text { (deg) } \\
\text { BN }\end{array}$ & BS & $\begin{array}{l}\text { Max. } \\
\text { Current } \\
\text { (Amps) }\end{array}$ \\
\hline 1 & 3000 & 40 & 40 & 9.61 \\
\hline 2 & 3000 & 38 & 40 & 9.55 \\
\hline 3 & 3000 & 38 & 38 & 9.46 \\
\hline 4 & 1500 & 40 & 40 & 4.80 \\
\hline 5 & 1500 & 38 & 40 & 4.78 \\
\hline 6 & 1500 & 38 & 38 & 4.73 \\
\hline 7 & 500 & 40 & 40 & 1.61 \\
\hline 8 & 500 & 38 & 40 & 1.60 \\
\hline 9 & 500 & 38 & 38 & 1.58 \\
\hline
\end{tabular}


Table 4 shows that more $I_{q}$ current is drawn with increasing severity of B-N and B-S contact angles. However, the margins become increasingly smaller between the $I_{q}$ currents (for respective contact angle cases) at lower speed demands.

These cases were classified as being healthy although it could be challenging to diagnose against early stages of deterioration, especially when operating at low speeds.

The mechanical system efficiency was changed to $70 \%$ with resulting maximum $I_{q}$ currents shown in Table 5. Contact angles for B-N and B-S at 40 degrees are also presented alongside the previous results with $80 \%$ efficiency. As can be seen, the variation in peak $I_{q}$ current becomes larger with speed due to the velocity dependent viscous friction coefficient.

Table 5. Maximum $I_{q}$ Currents Under Varying Mechanical System Efficiencies for All Speeds (Healthy States).

\begin{tabular}{llll}
\hline $\begin{array}{l}\text { Test } \\
\text { Case }\end{array}$ & $\begin{array}{l}\text { Demand } \\
\text { Speed } \\
\text { (RPM) }\end{array}$ & $\begin{array}{l}\text { Mechanical } \\
\text { System } \\
\text { Efficiency (\%) }\end{array}$ & $\begin{array}{l}\text { Max. } \\
\text { Current (A) }\end{array}$ \\
\hline 1 & 3000 & 70 & 10.97 \\
\hline 2 & 3000 & 80 & 9.61 \\
\hline 3 & 1500 & 70 & 5.49 \\
\hline 4 & 1500 & 80 & 4.80 \\
\hline 5 & 500 & 70 & 1.84 \\
\hline 6 & 500 & 80 & 1.61 \\
\hline
\end{tabular}

\section{$\underline{\text { Degrading State }}$}

Larger contact angle offsets were introduced (as specified in Table 3) to represent degrading cases to further analyse the effect on the $I_{q}$ currents. A sample of these cases is presented in Table 6.

Table 6. Maximum $I_{q}$ Currents Under Varying Contact Angles for All Speeds (Degrading States),

\begin{tabular}{lllll}
\hline Test Case & $\begin{array}{l}\text { Demand } \\
\text { Speed } \\
\text { (RPM) }\end{array}$ & $\begin{array}{l}\text { Contact Angle } \\
\text { (deg) } \\
\text { BN }\end{array}$ & $\begin{array}{l}\text { BS } \\
\text { Bax. } \\
\text { Current } \\
\text { (A) }\end{array}$ \\
\hline 1 & 3000 & 35 & 43 & 9.84 \\
\hline 2 & 3000 & 43 & 43 & 9.81 \\
\hline 3 & 3000 & 35 & 35 & 9.67 \\
\hline 4 & 3000 & 43 & 38 & 9.58 \\
\hline 5 & 1500 & 35 & 43 & 4.92 \\
\hline 6 & 1500 & 43 & 43 & 4.91 \\
\hline 8 & 1500 & 35 & 35 & 4.84 \\
\hline
\end{tabular}

\begin{tabular}{lllll}
\hline Test Case & $\begin{array}{l}\text { Demand } \\
\text { Speed } \\
\text { (RPM) }\end{array}$ & $\begin{array}{l}\text { Contact Angle } \\
\text { (deg) } \\
\text { BN }\end{array}$ & $\begin{array}{l}\text { BS } \\
\text { Max. } \\
\text { Current } \\
\text { (A) }\end{array}$ \\
\hline 9 & 500 & 35 & 43 & 1.65 \\
\hline 10 & 500 & 43 & 43 & 1.64 \\
\hline 11 & 500 & 35 & 35 & 1.62 \\
\hline 12 & 500 & 43 & 38 & 1.60 \\
\hline
\end{tabular}

Table 6 shows the progressive nature of the ballscrew degradation where $I_{q}$ currents are increasing with severity of contact angle offsets.

Variations in mechanical system efficiencies (for degrading conditions) were introduced and compared with a couple of examples of contact angle offsets. Table 7 shows the results of this where simulations were run at 3000 RPM command speed.

Table 7. Maximum $I_{q}$ Currents Under Varying Mechanical System Efficiencies at 3000 RPM (Degrading States).

\begin{tabular}{lllll}
\hline $\begin{array}{l}\text { Test } \\
\text { Case }\end{array}$ & \multicolumn{2}{l}{$\begin{array}{l}\text { Contact } \\
\text { Angle (deg) }\end{array}$} & $\begin{array}{l}\text { Mechanical } \\
\text { System } \\
\text { Efficiency (\%) }\end{array}$ & $\begin{array}{l}\text { Max. } \\
\text { Current } \\
\text { (A) }\end{array}$ \\
\cline { 2 - 4 } BN & BS & 35 & 22.48 \\
\hline 1 & 35 & 43 & 35 & 21.89 \\
\hline 2 & 43 & 38 & 35 & 14.31 \\
\hline 3 & 35 & 43 & 55 & 13.93 \\
\hline 4 & 43 & 38 & 55 & 11.24 \\
\hline 5 & 35 & 43 & 70 & 10.94 \\
\hline 6 & 43 & 38 & 70 & \\
\hline
\end{tabular}

Significantly higher current is drawn with reducing mechanical system efficiencies. Not only is this indicative of a severely degraded system, the risk of overcurrent becomes more probable (peak current of the PMSM rated at 28.7 A as specified in Table 1).

\section{Faulty State}

Lower values of mechanical system efficiencies were modelled to represent faulted states of the EMA. The results of which are shown in Table 8. 
Table 8. Maximum $I_{q}$ Currents Under Varying Contact Angles for All Speeds (Faulty) States).

\begin{tabular}{lllll}
\hline Test Case & $\begin{array}{l}\text { Demand } \\
\text { Speed } \\
\text { (RPM) }\end{array}$ & $\begin{array}{l}\text { Contact Angle } \\
\text { (deg) }\end{array}$ & $\begin{array}{l}\text { MN } \\
\text { Max. } \\
\text { Current } \\
\text { (A) }\end{array}$ \\
\hline 1 & 3000 & 35 & 35 & 31.55 \\
\hline 2 & 3000 & 43 & 43 & 31.41 \\
\hline 3 & 3000 & 38 & 38 & 30.27 \\
\hline 4 & 1500 & 35 & 35 & 15.77 \\
\hline 5 & 1500 & 43 & 43 & 15.71 \\
\hline 6 & 1500 & 38 & 38 & 15.14 \\
\hline 7 & 500 & 35 & 35 & 5.26 \\
\hline 9 & 500 & 43 & 43 & 5.23 \\
\hline
\end{tabular}

More specifically, the onset of ballscrew jamming was modelled by reducing the relative velocities between the ball and nut, and ball and screw. Table 9 shows the resulting maximum currents of such scenarios with simulations run at 3000 RPM demand speed.

Table 9. Maximum $I_{q}$ Currents for Reducing Relative Velocities Between Ball-Nut and Ball-Screw.

\begin{tabular}{lll}
\hline $\begin{array}{l}\text { Test } \\
\text { Case }\end{array}$ & Conditions & $\begin{array}{l}\text { Max. } \\
\text { Current } \\
\text { (A) }\end{array}$ \\
\hline 1 & $\begin{array}{l}\text { Relative velocities close to 0 in BN } \\
\text { and BS }\end{array}$ & 61.40 \\
\hline 2 & Relative velocities close to 0 in BS & 52.68 \\
\hline 3 & Relative velocities close to 0 in BN & 45.98 \\
\hline
\end{tabular}

Table 9 shows that significantly more $I_{q}$ currents are drawn when relative velocities (between B-N and B-S) are set close to zero. More $I_{q}$ current is drawn for ball-screw interaction especially as this is the most contentious area of friction in a ballscrew (Vahid-Araghi \& Golnaraghi, 2011).

Given the simulated data presented so far, further challenges become apparent which may lead to a misclassification of a health state. This can arise from data analysis of motor current signals where information relating to loads, operating speeds and quantification of system efficiency are unknown.

A misclassification can occur during an external disturbance such as gust or aeroloads.
Table 10. Example Misclassification Between Healthy and Degrading $I_{q}$ Currents at 500 RPM.

\begin{tabular}{lllll}
\hline $\begin{array}{l}\text { Test } \\
\text { Case }\end{array}$ & $\begin{array}{l}\text { Mechanical } \\
\text { System } \\
\text { Efficiency } \\
(\boldsymbol{\%})\end{array}$ & $\begin{array}{l}\text { External } \\
\text { Load }\end{array}$ & $\begin{array}{l}\text { Max. } \\
\text { Current } \\
(\mathbf{A})\end{array}$ & $\begin{array}{l}\text { Health } \\
\text { State }\end{array}$ \\
\hline 1 & 70 & Yes & 2.20 & Healthy \\
\hline 2 & 65 & No & 1.95 & Degrading \\
\hline
\end{tabular}

Table 10 shows an example of where, for the same demand speed, a misclassification can occur where the healthy signal experiences a higher $I_{q}$ current than the degrading one due to external load disturbances.

\subsection{Data Classification}

A total of $667 I_{q}$ current datasets were generated with each set processed to obtain peak current values (from steady state $\sim 2$ to 20 seconds cycle time) for training towards data classification.

The datasets were 'supervised' as the response to each set of variables are known i.e. Healthy, Degrading or Faulty. A sample set of peak $I_{q}$ currents at $3000 \mathrm{RPM}$ were plotted against their respective health state. The results are shown in Figure 15.

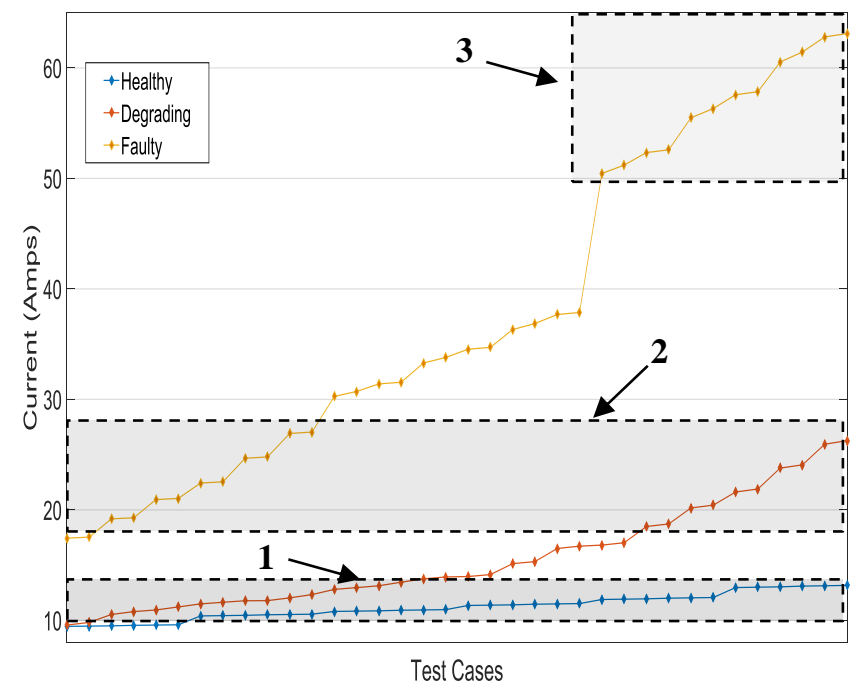

Figure 21. Sample Peak $I_{q}$ Currents at 3000 RPM.

Here it can be seen that the risk of misclassification is much higher between healthy and degrading datasets (as can be seen from the region labelled 1) due to the overlap in observations. False results are also possible for data generated in the lower bounds of the faulty data and higher bounds of the degrading data where the observations are 
overlapping (as can be seen from the region labelled 2). Despite the possibility of a misclassification, the actual health state of the EMA can be distinguishable outside regions 1 and 2. In particular, the onset of jamming can be predictable with such cases highlighted as shown in the region labelled 3.

In the context of aircraft maintenance of such systems, motor current and speed may be the only parameters available for diagnosis and fault detection during scheduled checks (Isturiz et al. 2012). Therefore, all peak $I_{q}$ currents and speeds were classified and plotted against their respective health state in a Confusion Matrix. The Confusion Matrix (Figure 22) was generated after training the data using k-NN classification algorithm to show the classification accuracy of these datasets given the conditions.

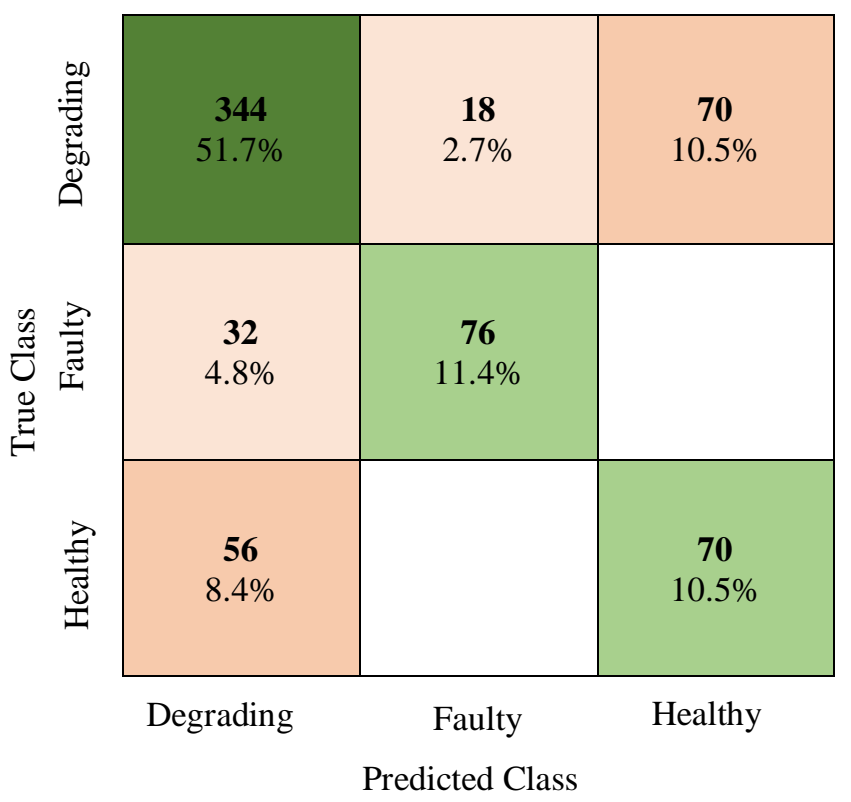

Figure 22. Confusion Matrix for Classifications with

Knowledge of $I_{q}$ Currents and Demand Speeds.

An overall classification accuracy of $73.6 \%$ was obtained. The red squares highlight instances of classification uncertainty from the simulated datasets. As can be seen, false results are most prevalent in cases where there is misclassification in data between Healthy and Degrading, and Degrading and Faulty states. It can also be seen that there are no misclassifications between Healthy and Faulted states.

The final step was to predict a classification (health state) based on the k-NN classifier for a new query. The queries to be evaluated were mainly based on situations where the data lies within a region of uncertainty of the trained classification. The queries to be tested are listed in Table 11.

Table 11. Queries to be Tested.

\begin{tabular}{ccc}
\hline Query & $\begin{array}{c}\text { Demand Speed } \\
(\text { RPM) }\end{array}$ & $\boldsymbol{I}_{\boldsymbol{q}}$ current (A) \\
\hline 1 & 500 & 2.1 \\
\hline 2 & 500 & 2.8 \\
\hline 3 & 500 & 4.2 \\
\hline 4 & 1500 & 5.1 \\
\hline 5 & 1500 & 12.3 \\
\hline 6 & 1500 & 12.7 \\
\hline 7 & 3000 & 10.1 \\
\hline 8 & 3000 & 23 \\
\hline 9 & 1000 & 10 \\
\hline 10 & 1850 & 21 \\
\hline 11 & 2600 & 9 \\
\hline
\end{tabular}

The first set of predictions were generated based on a k-NN classifier with a neighbourhood size of 1 . The results of this are presented in Table 12.

Table 12. Predicted Classifications Using 1 NN.

\begin{tabular}{cccc}
\hline Query & $\begin{array}{c}\text { Demand } \\
\text { Speed } \\
(\mathbf{R P M})\end{array}$ & $\begin{array}{c}\boldsymbol{I}_{\boldsymbol{q}} \text { current } \\
(\mathbf{A})\end{array}$ & $\begin{array}{c}\text { Predicted } \\
\text { Classification } \\
\text { (NN = 1) }\end{array}$ \\
\hline 1 & 500 & 2.1 & Degrading \\
\hline 2 & 500 & 2.8 & Degrading \\
\hline 3 & 500 & 4.2 & Faulty \\
\hline 4 & 1500 & 5.1 & Healthy \\
\hline 5 & 1500 & 12.3 & Faulty \\
\hline 6 & 1500 & 12.7 & Degrading \\
\hline 7 & 3000 & 10.1 & Degrading \\
\hline 8 & 3000 & 23 & Faulty \\
\hline 9 & 1000 & 10 & Degrading \\
\hline 10 & 1850 & 21 & Faulty \\
\hline 11 & 2600 & 9 & Healthy \\
\hline
\end{tabular}

A classifier can be more robust with more neighbours (Murphy, 2012) so a new set of predictions was generated for the same queries with increasing neighbourhood size. The results of this are shown in Table 13. Classifications highlighted in bold indicate a change in classification through each change in neighbourhood size value. 
Table 13. Predicted Classifications Using Different NN Values.

\begin{tabular}{|c|c|c|}
\hline \multirow[t]{2}{*}{ Query } & \multicolumn{2}{|c|}{ Pred } \\
\hline & $\mathbf{N N}=1$ & $\mathbf{N N}=2$ \\
\hline 1 & Degrading & Degrading \\
\hline 2 & Degrading & Degrading \\
\hline 3 & Faulty & Degrading \\
\hline 4 & Healthy & Healthy \\
\hline 5 & Faulty & Degrading \\
\hline 6 & Degrading & Degrading \\
\hline 7 & Degrading & Degrading \\
\hline 8 & Faulty & Degrading \\
\hline 9 & Degrading & Degrading \\
\hline 10 & Faulty & Faulty \\
\hline 11 & Healthy & Healthy \\
\hline \multicolumn{3}{|c|}{$\begin{array}{l}\text { As can be deduced from Table } 13 \text {, some queries exhibited } \\
\text { consistency in terms of predicted classification result i.e. } \\
\text { queries } 1,2,4,6,10 \text { and } 11 \text {. }\end{array}$} \\
\hline \multicolumn{3}{|c|}{$\begin{array}{l}\text { Inconsistency in predicted classification was evident for } \\
\text { queries } 3 \text { and } 8 \text { in particular where ascertaining the true state } \\
\text { of health was difficult given the variation in classification of } \\
\text { the nearest respective neighbours. Due to the uncertainty of } \\
\text { these queries, such classifications can be deemed } \\
\text { inconclusive as they can give rise to false predictions. }\end{array}$} \\
\hline
\end{tabular}

\section{DISCUSSION}

Based on the simulations, the findings of this investigation indicate that certain features of ballscrew degradation could be identified through analyzing $I_{q}$ currents from high fidelity modelling of dynamic behaviour of the motor and nonlinearities in the ballscrew.

The PMSM peak starting current was predicted and shown to be a feature that will vary with speed and load from which could be identifiable through 3 -phase and $I_{q}$ currents. Gao and Kang (2014) conducted modelling and simulation of a PMSM through vector control techniques and also demonstrated this peak starting current behaviour as was illustrated in Figure 11.

The Stribeck friction effect was also modelled in the ballscrew. Through simulation, an additional peak current (due to the Stribeck effect) was identifiable during the acceleration. This condition is indicative of the transition between static and kinetic friction. Degrading features could be ascertained from analyzing this peak current which could then be attributed to the presence of static friction within the contact zones in the ballscrew. Figures 13 and 14 demonstrated this effect. Experimental work previously conducted by Jeong and Cho (2002) also highlighted these frictional effects at low velocities as was shown in Figures 16
Predicted Classification

$\mathrm{NN=3} \quad \mathrm{NN}=5 \quad \mathrm{NN}=10$

\begin{tabular}{lcc}
\hline Degrading & Degrading & Degrading \\
\hline Degrading & Degrading & Degrading \\
Faulty & Degrading & Degrading \\
\hline Healthy & Healthy & Healthy \\
\hline Degrading & Degrading & Degrading \\
\hline Degrading & Degrading & Degrading \\
\hline Degrading & Healthy & Degrading \\
\hline Faulty & Degrading & Degrading \\
\hline Faulty & Degrading & Degrading \\
\hline Faulty & Faulty & Faulty \\
\hline Healthy & Healthy & Healthy \\
\hline
\end{tabular}

and 18. Therefore, the level of ballscrew stiction could be monitored through analysis of $I_{q}$ currents during acceleration.

The effects of viscous friction within the ballscrew were also modelled as was shown in Figures 19. The ballscrew mechanical efficiency could be ascertained through motor current. As evident in Figure 19, this is a velocity dependent friction component, therefore, more current was drawn at higher speeds. Evaluation of these features can provide information regarding the overall ballscrew condition with respect to wear and degradation through service life.

The effects of load were considered to simulate the effects of external loads such as aeroloads from a real application. Given the knowledge about operating speed, load torque could also be inferred through motor current. Jeong and Cho (2002) also demonstrated this feature for a ballscrew driven milling machine as a function of varying cutting forces.

Through simulation, it was also found that analysing a time domain $I_{q}$ current signal could reveal information regarding ballscrew geometry which may otherwise be challenging to detect in a 3-phase current signal (as was shown in Figure 20). Following this, data classification techniques were applied to classify simulated data of peak $I_{q}$ currents in steady state conditions (after peak starting current) for different ballscrew contact angles and mechanical efficiencies using k$\mathrm{NN}$ classification algorithm. A classification of $\sim 74 \%$ was achieved following simulations of 667 peak $I_{q}$ currents. The performance of this was also tested with new queries. Misclassifications were apparent and increasing the dimensionality of the classifier by including peak starting current information may improve the predictive accuracy.

This can be achieved through characterisation and a deeper analysis of losses within the motor. For gear-driven systems, high-fidelity modelling of the gearbox should also be considered. The analysis involved evaluating dynamic behaviour during transient and steady state operation for a 
trapezoidal speed profile. It is therefore recommended to consider a load profile from a real system i.e. a landing gear extension/retraction system and pursue a similar approach.

\section{ConClusions}

Simulated data were generated from a detailed Matlab/Simulink EMA model and used for data classification using the k-NN algorithm. The EMA was modelled for speed and current control with the PMSM modelled using $d q$ axis transform theory, which enabled analysis using $I_{q}$ currents. The Stribeck model was included as a means to evaluate friction at a local level of the ballscrew as a function of relative velocities between the ball and nut, and the ball and screw.

The EMA model was able to detect changes to the ballscrew contact angles and geometry as well as variation in mechanical system efficiencies using $I_{q}$ currents. The risk of misclassification was greater when simulations were run with external load disturbances added in. This can make it difficult to detect variations in contact geometry and efficiencies.

The simulated data was trained and classified using the k-NN algorithm. A classification accuracy of $\sim 74 \%$ was obtained using knowledge of $I_{q}$ currents and demand speeds alone.

The model could be further improved by considering a tribology-based approach to the friction analysis by evaluating contact pressures between the contact zones in the ballscrew. This can be viewed as a follow-on to the detailed kinematic analysis and a validation step to the velocity dependent friction model. New queries may be predicted from real-time data as a means to further assess the performance of the k-NN classifier presented.

It is proposed that the approach outlined in this paper can be utilised in conjunction with a test stand. By this, 3-phase current signals could be obtained to analyse through Park's transform which could then enable one to estimate friction parameters for the motor and ballscrew. Ballscrew dynamic behaviour could then be characterized through analyzing static friction at low velocities, ballscrew wear as well as load torque through motor current alone. A hybrid approach to diagnostics could also be satisfied by capturing any discrepancy between model based results and actual data, which can also help to isolate faults within the EMA drivetrain.

\section{ACKNOWLEDGEMENT}

This work was supported by the Systems Centre and the EPSRC funded Industrial Doctorate Centre in Systems (Grant EP/G037353/1) and Stirling Dynamics.

\section{REFERENCES}

Armstrong-Helouvry, B., Dupont, P., \& De Wit, C. (1994). A Survey of Models, Analysis Tools and
Compensation Methods for the Control of Machines with Friction. Automatica Volume 30, 1083-1138.

Balaban, E., Saxena, A., Bansal, P., Goebel, K., Curran, S., \& Stoelting, P. (2009). A Diagnostic Approach for Electromechanical Actuators in Aerospace Systems.

Balaban, E., Saxena, A., Goebel, K., Byington, C., Watson, M., Bharadwaj, S., and Smith, M. (2009).

Experimental Data Collection and Modelling for Nominal and Fault Conditions on Electromechanical Actuators. PHM.

Balaban, E., Saxena, A., Narasimhan, S., Roychoudhury, I., and Goebel, K. (2011). Experimental Validation of a Prognostic Health Management System for Electro-Mechanical Actuators. American Institute of Aeronautics and Astronautics.

Bennett, J., Mecrow, B., Atkinson, D., and Atkinson, G. (2010). Safety-critical design of electromechanical actuation systems in commercial aircraft. IET Electric Power Applications, 37-47.

Bodden, D. S., Clements, S., Schley, B., and Jenney, G. (2007). Seeded Failure Testing and Analysis of an Electromechanical Actuator. Aerospace Conference IEEE, 1-8.

Boeing. (1994). 757 Operations Manual. Seattle: The Boeing Company.

Bowden, F., and Tabor, D. (1950). The Friction and Lubrication of Solids. Oxford: Oxford University Press.

Donald, S., Garg, S., Hunter, G., Guo, T.-H., and Semega, K. (2004). Sensor Needs for Control and Health Management of Intelligent Aicraft Engines. NASA Technical Paper.

Gao, J., \& Kang, J. (2014). Modeling and Simulation of Permanent Magnet Synchronous Motor Vector Control. Information Technology Journal, 578-582.

Hoffman, A., Hansen, I., Beach, R., Plencner, R., Dengler, R., Jefferies, K., and Frye, R. (1985). Advanced Secondary Power System for Transport Aircraft. NASA Technical Paper.

Ismail, M., Balaban, E., and Spangenberg, H. (2016). Fault Detection and Classification for Flight Control Electromechanical Actuators. Aerospace Conference. IEEE.

Isturiz, A., Vinals, J., Manuel, A., and Aitzol, I. (2012). Health Monitoring Strategy for Electromechanical Actuator Systems and Components, Screw Backlash and Fatigue Estimation. Recent Advances in Aeropsace Actuation Systems and Components. 
Jeong, Y., \& Cho, D. (2002). Estimating Cutting Force from Rotating and Stationary Feed Motor Currents on a Milling Machine. International Journal of Machine Tools and Manufacture, 1559-1566.

Jiang, H., Song, X., Xu, X., Tang, W., Zhang, C., and Han, Y. (2010). Multibody dynamics simulation of Balls impact-contact mechanics in Ball Screw Mechanism. 2010 International Conference on Electrical and Control Engineering (pp. 13201323). IEEE.

Karter, J. (2016). Machine Learning, Design of Experiments and Statistical Process Control using Matlab. Create Space Independent Publishing Platform.

Lee, W., Lee, J., Hong, M., Nam, S., Jeon, Y., and Lee, M. (2015). Failure Diagnosis System for a Ball-Screw by Using Vibration Signals. Hindawi Shock and Vibration.

Maggiore, P., Vedova, M., Pace, L., \& Desando, A. (2014). Definition of Parametric Methods for Fault Analysis applied to an Electromechanical Servomechanism affected by Multiple Failures. European Conference of the Prognostics and Health Management Society. PHM.

McNier, T. (2016). Specifying, Selecting and Applying Linear Ball Screw Drives. Thomson.

Murphy, K. (2012). Machine Learning, A Probabalistic Perspective. The MIT Press.

Ninomiya, M., and Miyaguchi, K. (1998). Recent Technical Trends in Ball Screws. NSK Technical Journal: Motion Control, 1-3.

Park, R. H. (1929). Two Reaction Theory of Synchronous Machines. AIEE Transactions 48, 716-730.

Song, X., Jian, L., Zhao-tan, W., Xian-yin, L., and Bao-min, L. (2005). Research and Development of Test System of Combination Property of High-Speed Ball Screw Unit. Tool Engineering, 34-36.

THK. (2017). Retrieved from Linear Motion Tips: http://www.linearmotiontips.com/what-is-backdriving-and-why-is-it-important/

Vahid-Araghi, O., and Golnaraghi, F. (2011). FrictionInduced Vibration in Lead Screw Drives. Springer.

Vas, P. (1996). Electrical Machines and Drives: A SpaceVector Theory Approach. Oxford.

Wei , C., and Lin, J. (2004). Kinematic Analysis of the Ball Screw Mechanism Considering Variable Contact Angles and Elastic Deformations. ASME Journal of Mechanical Design, 717-733.

Xu, S., Yao, Z., Sun, Y., and Shen, H. (2014). Load Distribution of Ball Screw With Consideration of Contact Angle Variation and Geometry Errors.

\begin{abstract}
International Mechanical Engineering Congress and Exposition. ASME.
\end{abstract}

\section{BIOGRAPHIES}

Yameen Monsur Hussain received a BEng (Hons) in Aviation Engineering from Brunel University, London in 2010 and MSc in Fluid Power Systems from the University of Bath in 2011. He is currently an Engineering Doctorate (EngD) student at the University of Bristol studying Health Monitoring of Electrical Actuation Systems in collaboration with Stirling Dynamics Ltd. His current research interests are prognostics and health management techniques, reliability, electromechanical actuation, tribology and optimisation of maintenance scheduling.

Stephen G Burrow received the MEng and PhD degrees in electrical engineering from the University of Bristol in 1998 and 2002, respectively. He is currently a Reader in the Department of Aerospace Engineering, University of Bristol. His current research encompasses power electronics, machines and energy harvesting, and environmental sensing.

Leigh Henson received a BEng (Hons) degree in Mechanical Engineering from the University of Huddersfield in 2002 including a twelve month industrial placement at AgustaWestland Helicopters (now Leonardo). Awarded Chartered Engineer (CEng) status as a member of the Institute of Mechanical Engineers (IMechE) in 2006 after four years post graduate experience in the civil aerospace industry with Airbus. Working for Stirling Dynamics has built extensive experience in Landing Gear Systems covering research and technology, new aircraft/equipment development and qualification including: requirements capture, V\&V process, first flight, flight test, certification, entry into service (EIS) and continuous product development (CPD).

Patrick Keogh received degrees from the universities of Nottingham and Manchester. He was a Research Technologist at the Engineering Research Centre, GEC Alsthom (now Alstom). In 1990, he joined the Department of Mechanical Engineering, University of Bath, Bath, U.K. His current research interests include rotor dynamics, magnetic bearing systems, active vibration control, modern optimal control for multivariable systems, contact dynamics, and associated thermal behaviour of bearings.

\section{APPENDIX}

i. Motor Modelling Equations

Firstly, the 3-phase supply voltages were converted to 2phase quantities using Park's transform: 
$\left[\begin{array}{l}V_{d} \\ V_{q} \\ V_{0}\end{array}\right]=\frac{2}{3}\left[\begin{array}{ccc}\cos \theta & \cos \left(\theta-\frac{2 \pi}{3}\right) & \cos \left(\theta+\frac{2 \pi}{3}\right) \\ -\sin \theta & -\sin \left(\theta-\frac{2 \pi}{3}\right) & -\sin \left(\theta+\frac{2 \pi}{3}\right) \\ \frac{1}{2} & \frac{1}{2} & \frac{1}{2}\end{array}\right]\left[\begin{array}{l}V_{a} \\ V_{b} \\ V_{c}\end{array}\right]$

The PMSM electrical model consists of the stator resistance, inductances ( $\mathrm{d}$ and $\mathrm{q}$ axes), number of poles as well as the flux induced by the rotor permanent magnets in the stator phases to get the $I_{q}$ and $I_{d}$ currents:

$V_{d}=R_{s} I_{d}+p \lambda_{d}-\omega_{r} \lambda_{q}$

$V_{q}=R_{s} I_{q}+p \lambda_{q}+\omega_{r} \lambda_{d}$

Where

$\lambda_{d}=L_{d} I_{d}+\lambda_{a f}$

and

$\lambda_{q}=L_{q} I_{q}$

The electromagnetic torque of the PMSM is derived from:

$T_{e}=\frac{3 p}{4}\left(\lambda_{d} I_{q}-\lambda_{q} I_{d}\right)=\frac{3 p}{4}\left(\lambda_{a f} I_{q}+\left(L_{d}-L_{q}\right) I_{d} I_{q}\right)$

The mechanical subsystem of the PMSM model to calculate mechanical torque and rotor mechanical speed is given by

$T_{e}=T_{L}+B \omega_{m}+J \frac{d \omega_{m}}{d t}$

Equation (9û) can be rearranged for rotor mechanical speed:

$\omega_{m}=\int\left(\frac{T_{e}-T_{L}-B \omega_{m}}{J}\right) d t$

whereby the relationship between the electrical speed $\left(\omega_{r}\right)$ and the rotor mechanical speed $\left(\omega_{m}\right)$ is given by

$\omega_{m}=\omega_{r}\left(\frac{2}{p}\right)$

Given the modelled PMSM electrical and mechanical properties, the $\mathrm{d}$ and $\mathrm{q}$ axis currents are transformed back into 3-phase quantities and subsequently fed back in to the PMSM controller block (as shown in Figure 2). The inverse Park transform was used to return the 3-phase currents:

$\left[\begin{array}{l}I_{a} \\ I_{b} \\ I_{c}\end{array}\right]=\left[\begin{array}{ccc}\cos \theta & -\sin \theta & 1 \\ \cos \left(\theta-\frac{2 \pi}{3}\right) & -\sin \left(\theta-\frac{2 \pi}{3}\right) & 1 \\ \cos \left(\theta+\frac{2 \pi}{3}\right) & -\sin \left(\theta+\frac{2 \pi}{3}\right) & 1\end{array}\right]\left[\begin{array}{c}I_{d} \\ I_{q} \\ I_{0}\end{array}\right]$

\section{ii. Ballscrew Modelling Equations}

For this analysis, the total system inertia is given the summation of motor, ballscrew and load inertia:

$J=J_{m}+J_{B S}+J_{l}$
$J_{m}$ is known from the motor manufacturer specification as given in Table 1. $J_{B S}$ was modelled as a cylinder based on density, radius and length:

$J_{B S}=\frac{\pi l \rho D_{S}^{4}}{32}$

$J_{l}$ is the load inertia reflected back to the motor:

$J_{l}=\frac{m L^{2}}{2 \pi} \times 10^{-6}$

The load torque reflected to the motor is composed by the load force, $F_{l}$ and pre-load force, $F_{p f}$.

$\tau_{r}=\frac{F_{l} L}{2 \pi \eta}+\mu \frac{F_{p f} L}{2 \pi \eta}$

The relative velocities between ball and screw, $V_{B S}$ and ball and nut $V_{B N}$, needed to be factored in. Relative speeds of these regions are critical for this study as they largely dictate the magnitude of instability when the ballscrew experiences a fault (Jiang, Song, Xu, Tang, Zhang \& Han, 2010). The corresponding relative angular velocities are given by

$\omega_{B S}=\frac{V_{B S}}{0.5\left(d_{S}-D\right)}$

$\omega_{B N}=\frac{V_{B N}}{0.5 d_{n}}$

Information regarding the rotor mechanical speed, $\left(\omega_{m}\right)$ is known therefore the angular velocities were calculated using a detailed kinematic analysis. Wei and Lin (2004) determined the relationship between the angular velocities, $\omega_{B S}$ and $\omega_{B N}$ as

$\frac{\omega_{B S}}{\omega_{B N}}=\frac{\left(1+\delta \cos \alpha_{n}\right)\left(\cos \alpha_{S}+\tan \beta \sin \alpha_{S}\right)}{\left(1-\delta \cos \alpha_{S}\right)\left(\cos \alpha_{n}+\tan \beta \sin \alpha_{n}\right)}$

$\beta$ is the lead angle and $\delta$ is a relationship between ball diameter and screw pitch given by

$\delta=\frac{D}{d_{s}}$

The contact angles (between ball and nut, $\alpha_{n}$, and ball and screw, $\alpha_{s}$ ) are depicted in Figure 6.

In order to calculate the relative angular velocities $\left(\omega_{B S}\right.$ and $\left.\omega_{B N}\right)$, ball linear velocity, $V_{b}$ needs to be ascertained. Assuming the relative slip speed between ball and nut is negligible, $V_{b}$ can be calculated as follows (Song, Jian, Zhaotan, Xian-yin \& Bao-min 2005):

$V_{b}=\frac{\omega_{m}\left(D_{s}-D \sin \alpha\right) \cos \beta}{2}$

Where the lead angle, $\beta$ is determined from 
$\tan \beta=\frac{L}{\pi D}$

Given equation (21), the corresponding ball angular velocity, $\omega_{b}$ is given by:

$\omega_{b}=\frac{V_{b}}{0.5 d_{s}}$

The relative angular velocity between ball and screw, $\omega_{B S}$ depends on ball angular velocity, $\omega_{b}$ and ballscrew angular velocity, $\omega_{m}$ (Wei \& Lin, 2004), hence

$\omega_{B S}=\left(\omega_{m}-\omega_{b}\right) \cos \alpha$

The relative angular velocity between ball and nut, $\omega_{B N}$ depends only on the ball angular velocity, $\omega_{b}$ (Wei \& Lin, 2004) therefore:

$\omega_{B N}=-\omega_{b} \cos \alpha$

Given that $\omega_{\mathrm{BS}}$ and $\omega_{\mathrm{BN}}$ can now be calculated as a function of ball angular velocity, $\omega_{\mathrm{b}}$, equations (24) and (25) can be substitued into equation (19) and rearranged to obtain

$\omega_{B S}=\omega_{B N} \frac{\left(1+\delta \cos \alpha_{n}\right)\left(\cos \alpha_{s}+\tan \beta \sin \alpha_{S}\right)}{\left(1-\delta \cos \alpha_{S}\right)\left(\cos \alpha_{n}+\tan \beta \sin \alpha_{n}\right)}$
$\omega_{B N}=\omega_{B S} \frac{\left(1-\delta \cos \alpha_{S}\right)\left(\cos \alpha_{n}+\tan \beta \sin \alpha_{n}\right)}{\left(1+\delta \cos \alpha_{n}\right)\left(\cos \alpha_{s}+\tan \beta \sin \alpha_{s}\right)}$

iii. Matlab Code for k-NN Classifier.

load simulateddata

$\mathrm{X}=$ meas; oall motor current and speed

data

$Y=$ responses $\%$ corresponding state of

health of each simulation

$\operatorname{mdl}=$ ClassificationKNN.fit $(X, Y) ; \% k-N N$

classification

mdl. NumNeighbours $=1$; \%set number of

nearest neighours, default value is 1

o Predict the classification for a new

query

queryl = [500 2.2] ; oxample query for

500 RPM and $2.2 \mathrm{~A}$

querylClass $=$ predict (mdl, queryl); \%class

prediction 